\title{
Linear low density polyethylene (LLDPE) films containing perylene dyes as stress-strain luminescent indicators
}

\author{
Andrea Pucci, ${ }^{1 *}$ Filippo Donati, ${ }^{1}$ Giacomo Ruggeri, ${ }^{123}$ Francesco Ciardelli ${ }^{2}$ \\ ${ }^{1 *}$ Dipartimento di Chimica e Chimica Industriale, Università di Pisa, Via Risorgimento \\ 35, 56126 Pisa, Italy. Tel: +39 0502219270; fax: +39 0502219320; e-mail: \\ apucci@ns.dcci.unipi.it \\ ${ }^{2}$ PolyLab-CNR, c/o Dipartimento di Chimica e Chimica Industriale, Università di Pisa, \\ via Risorgimento 35, I-56126 Pisa, Italy. \\ ${ }^{3}$ INSTM, Unità di Ricerca di Pisa, Via Risorgimento 35, 56126 Pisa, Italy
}

(Received: 22 December, 2007; Published: 08 June 2009)

\begin{abstract}
Linear low density polyethylene (LLDPE) films containing different concentrations of perylene $(P)$ chromophores have been prepared by solution-casting and compression-moulding. The light emission features of the films depend on $\mathrm{P}$ concentration and polymer films deformation. A well-defined band attributed to the formation of micro/ nano-structured perylene chromophoric aggregates is observed with more than $0.1 \mathrm{wt} \%$ of $P$ in the film. The occurrence of this phenomenon changed the emission colour of the films from a bright blue (noninteracting dyes) to low intense pale yellow (interacting dyes) colour. During film drawing the LLDPE macromolecules reorganization is able to break the $P$ supramolecular organization, leading to the prevalence of the blue emission of monomeric P. The optical behaviour of perylene dyes acting as internal stressstrain luminescent indicators for polyethylene films, provides a powerful tool to detect macromolecular organization.
\end{abstract}

\section{Introduction}

In recent years the research of new, easy and effective methods for the determination of external contaminations of plastic packages has steeply grown. For example, highly sensitive optical techniques based on the luminescence of conjugated aromatic molecular additives dispersed at low concentration (<1-2 wt. \%) into the amorphous phase of thermoplastic polymers were successfully applied for the detection mechanical solicitations on plastic films [1-6]. On the other side considerable research has been devoted to study the optical properties of systems based on organic conjugated dyes dispersed in macromolecular matrices. The absorption and/or emission behaviour of the embedded chromophore provide also detailed information on the relaxations and melting transitions of the continuous polymer matrix [7-9]. Generally pyrene or perylene dyes are selected as fluorescent probes due to their long lifetime, high monomer and excimer quantum yields, and strong environmental effects upon emission properties.

In particular, luminescent dyes incorporated into polymers as thermodynamically stable micro/nano sized aggregates of few molecules show emission characteristics coming mostly from the fluorescence of interacting chromophores through $\pi-\pi$ stacking interaction among the planar aromatic backbones. On applying a mechanical deformation to the composite polymeric film, the shear-induced mixing between the continuous macromolecular matrix and the dispersed phase promotes 
the break-up of dye aggregates and the prevalence of the emission coming from isolated non-interacting chromophores, leading to a clear change of the material emission properties [6]. As luminescent additives incorporated into polymers for sensing applications, oligo(p-phenylene vinylene) $[1-3,10,11]$ and stilbene derivatives $[5,6,12]$ were the most exploited due to their fluorescence response that is highly dependent on the chromophore aggregation extent.

Among this class of dyes, considerable attention has been recently devoted in literature to perylene based chromophores due to the effective combination of properties ranging from electro-optical and redox characteristics and thermal and migration stability [13]. Perylene molecules consist of planar five benzene rings fused together whose structure and electronic conformation strongly promote the formation of chromophoric aggregates through stacking interactions between the conjugated cores [14]. Perylene derivatives are generally employed into various optoelectronic applications thanks to their thermal and photostability as for example fluorescence standards, thin film transistors, liquid crystals, light emitting diodes and devices for photovoltaics [15].

In this work, the perylene chromophore was used as a new and innovative luminescent probe for detecting plastic films deformation. The dye were dispersed by solution-casting and compression-moulding into linear low density polyethylene (LLDPE) at different concentrations. All the prepared films were studied in terms of their absorption and emission behaviour, dye concentration and polymer deformation, and the results were discussed in terms of their use as highly sensitive polyethylene indicators to mechanical solicitations.

\section{Results and discussion}

\section{Optical characterization in solution}

Perylene dye dissolved into an apolar and non-interacting solvent such as heptane showed three pronounced absorption peaks in the range of $380-440 \mathrm{~nm}$ and a shoulder at around $366 \mathrm{~nm}$, which correspond respectively to the $0-0,0-1,0-2$, and 0-3 vibronic transitions (Figure 1).

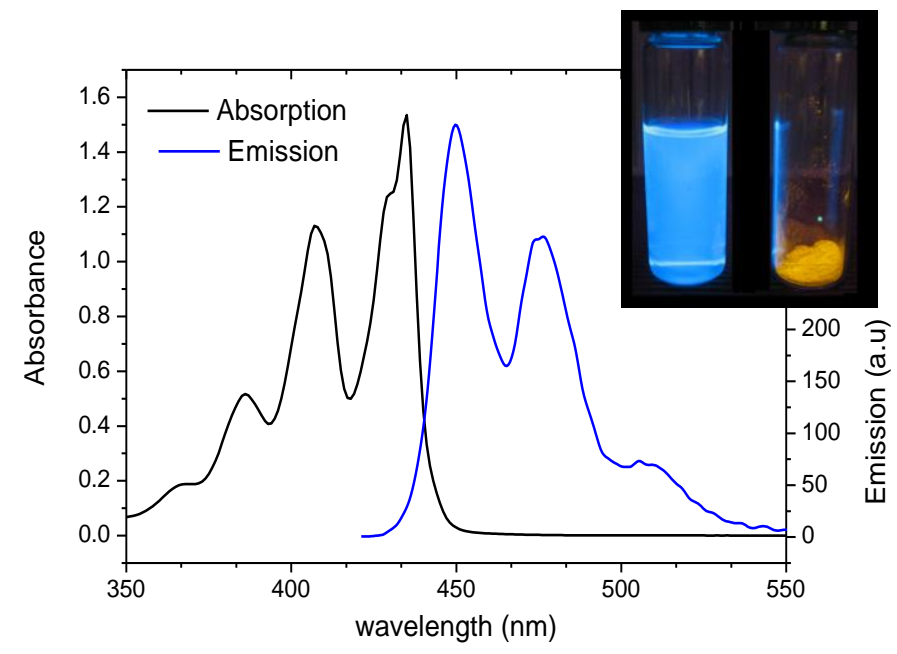

Fig. 1. UV-Vis absorption (black curve) and fluorescence spectra (blue curve, $\lambda_{\text {exc. }}=$ $300 \mathrm{~nm}$ ) of perylene in 5.10-5 M n-heptane solution. Inset: image of perylene in 5.10$4 \mathrm{M} \mathrm{n}$-heptane solution (left) and in the neat state (right). 
The fluorescence spectrum reported in Figure 1 depicted the same peak structure in a mirror image of the absorption with emission maxima at about 450 and $475 \mathrm{~nm}$. In both absorption and emission spectra the optical intensities increased with chromophore concentration and no bands attributed to the formation of chromophoric aggregates were detected in the investigated range of concentration $\left(10^{-6}-10^{-3} \mathrm{M}\right)$.

As reported in the inset of Figure 1, the heptane solutions emit blue light when excited by a long-range UV radiation at $366 \mathrm{~nm}$, whereas the perylene powder shows a bright orange-yellow color due most likely to the formation of chromophore aggregates of the planar condensated benzene rings.

\section{Optical properties of LLDPE based films}

10-30 $\mu \mathrm{m}$ thick linear low density polyethylene (LLDPE) films containing different concentrations of perylene (0.01-1 wt.\% of dye) were prepared by compression moulding of the respective LLDPE-dye mixtures, obtained by solution casting from xylene dispersions.

P-LLDPE composite films displayed absorption features analogue to that shown by heptane solution showing the typical absorption peaks of the isolated non-interacting chromophores at 390, 410 and $440 \mathrm{~nm}$ (Figure 2). Differently from solution, an unstructured band emerged at about $470 \mathrm{~nm}$ for LLDPE films containing more than $0.5 \mathrm{wt} . \% \mathrm{P}$. This last absorption was attributed to the formation of nano/micro-sized dye aggregates within the continuous apolar matrix and it was likely favoured by the $\pi-\pi$ stacking interactions between the perylene molecules. In solution, the formation of dye aggregates was avoided due to the high chromophore diffusion rate with respect to the excited state lifetime $[16,17]$. By contrast, the low diffusion rate of $P$ into LLDPE matrix promoted the aggregation of at least two dyes with inter-planar distance between their conjugated structure of about 3-4 $\AA[18,19]$.

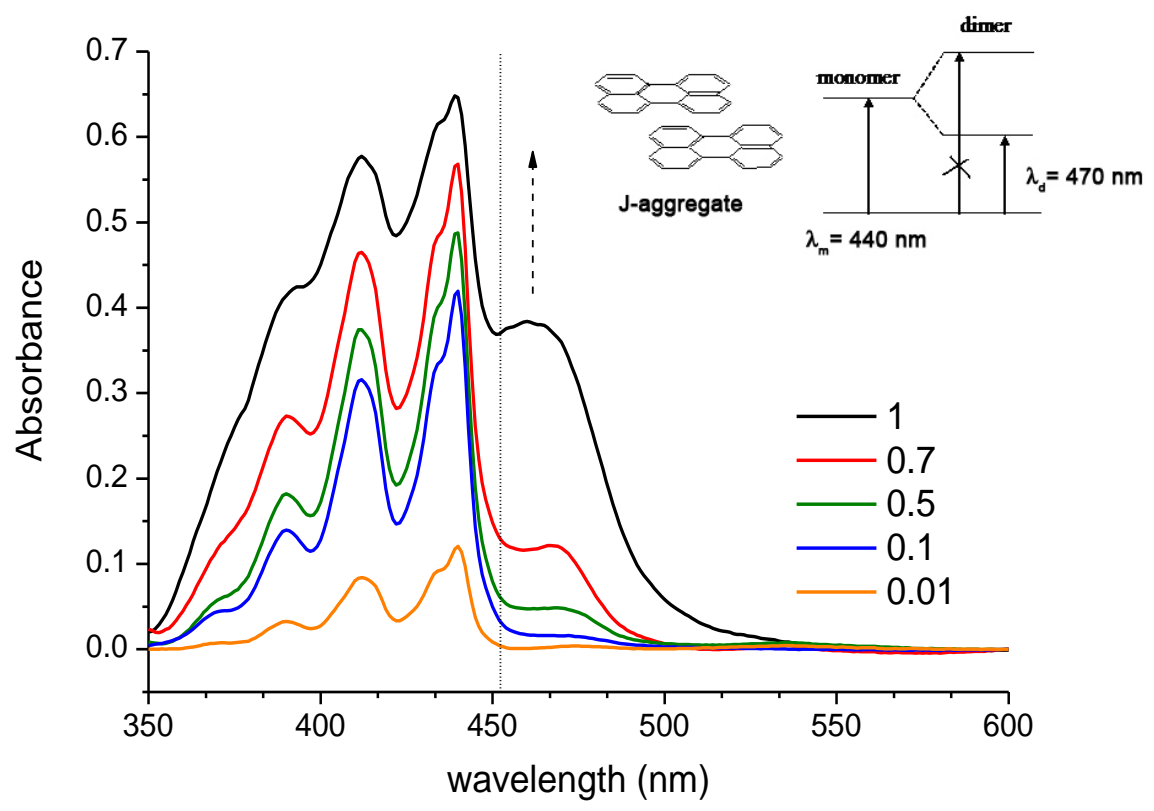

Fig. 2. (a) UV-Vis absorption of P-LLDPE films at different dye concentration (wt.\%) and graphical representation for perylene J-type aggregates (inset) 
By assuming the exciton theory $[17,20,21]$ to be valid the absorption band at about $470 \mathrm{~nm}$ can be explained as the result of the coupling between the two transition densities of the monomer when forming a dimer aggregate. According to this theory, the position of the dimer band with respect to that of the monomer depends on the mutual position of the two interacting monomers; our experimental data (also shown in the inset of Figure 2) suggest the formation of J-type aggregates [22,23].

The fluorescence spectra of P-LLDPE composite films containing the 0.01 and 0.1 wt.\% of perylene chromophore showed (Figure 3) the emission of P chromophores similar to heptane solutions displaying luminescent bands of non-interacting dyes pointed at about 450 and $475 \mathrm{~nm}$ and emission rising in intensity with $P$ loading (Figure 2, arrow 1). In particular, the $10 \mathrm{~nm}$ red-shift of the $0-0$ radiative transition band (from $450 \mathrm{~nm}$ to about $460 \mathrm{~nm}$ ) occurred with increasing $P$ concentration, flanked by the decreasing of the ratio between the intensity of 0-0 and 0-1 relaxations (compare the emission reported in Figure 1), was attributed to self absorption phenomena [24].

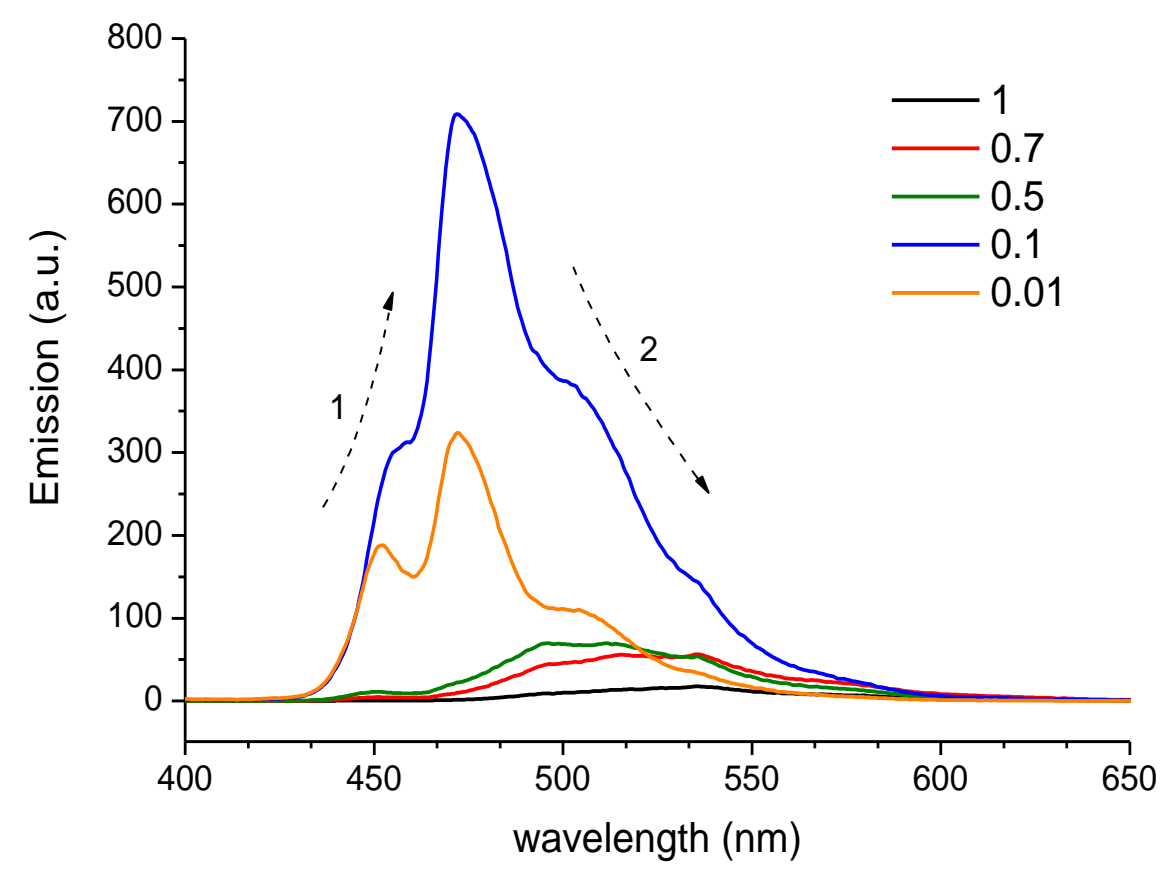

Fig. 3. (a) Emission spectra of P-LLDPE films at different dyes concentration (wt.\%, $\lambda_{\text {exc. }}=300 \mathrm{~nm}$ ).

In contrast, by increasing perylene concentration from 0.1 to $1 \mathrm{wt} . \%$, the fluorescence of the P-LLDPE films resulted progressively quenched in the range of wavelengths investigated. In particular, for P-LLDPE-0.5 and P-LLDPE-0.7 the emission was only detected from about 500 to $550 \mathrm{~nm}$ and attributed to the luminescence generated only by $\mathrm{P}$ chromophoric aggregates. For $\mathrm{P}$ concentration higher than $0.7 \mathrm{wt} . \%$ the emission coming from P-LLDPE films resulted mostly quenched according to the very strong $\pi-\pi$ packing behaviour among perylene chromophores (Figure 3, arrow 2).

The occurrence of supramolecular chromophore interactions among perylene LLDPE composites was also visually detected by exciting the samples with a long-range UV lamp at $366 \mathrm{~nm}$. The colour of the tapes changed actually from blue (associated to 
non-interacting perylene dyes) to pale yellow (associated to perylene aggregates) with increasing concentration (Figure 4).

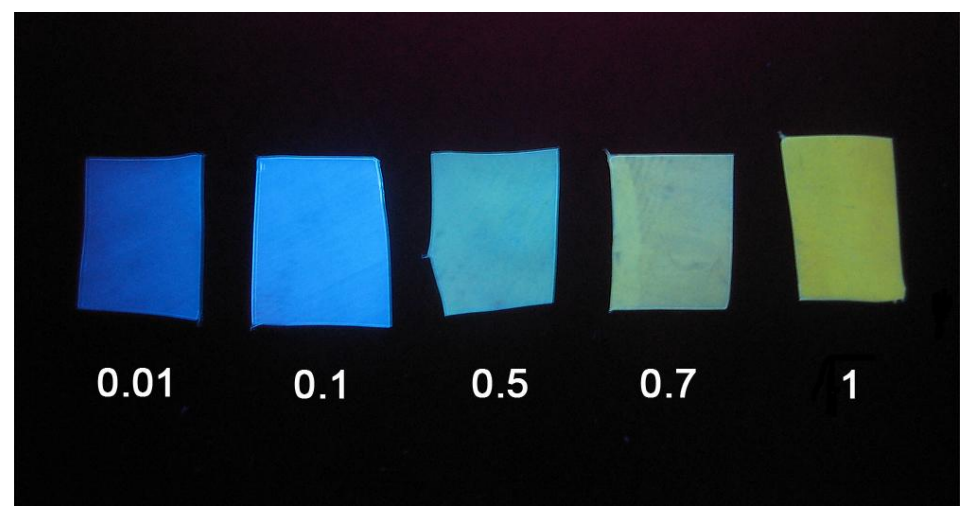

Fig. 4. Digital image of $P$-LLDPE containing different $P$ content (wt.\%) films taken under irradiation at $366 \mathrm{~nm}$.

\section{Effect of mechanical deformation}

The optical properties of LLDPE composite films were also evaluated after applying a mechanical uniaxial deformation at room temperature or at $90{ }^{\circ} \mathrm{C}$. It is well established that during drawing the macromolecules in the semicrystalline structure unfold leading to the formation of microfibrils consisting of oriented crystalline and amorphous regions [25]. As a consequence, dyes dispersed into the amorphous phase of polymers as isolated or interacting chromophores follow the macromolecular reorganization and are aligned along the drawing direction [26-28].

For example, the mechanical drawing of a P-LLDPE-0.7 film (Figure 5) reduces the thickness of the films and therewith their optical density (generally the thickness of the oriented films is at least 4 times smaller than that of the pristine tape).

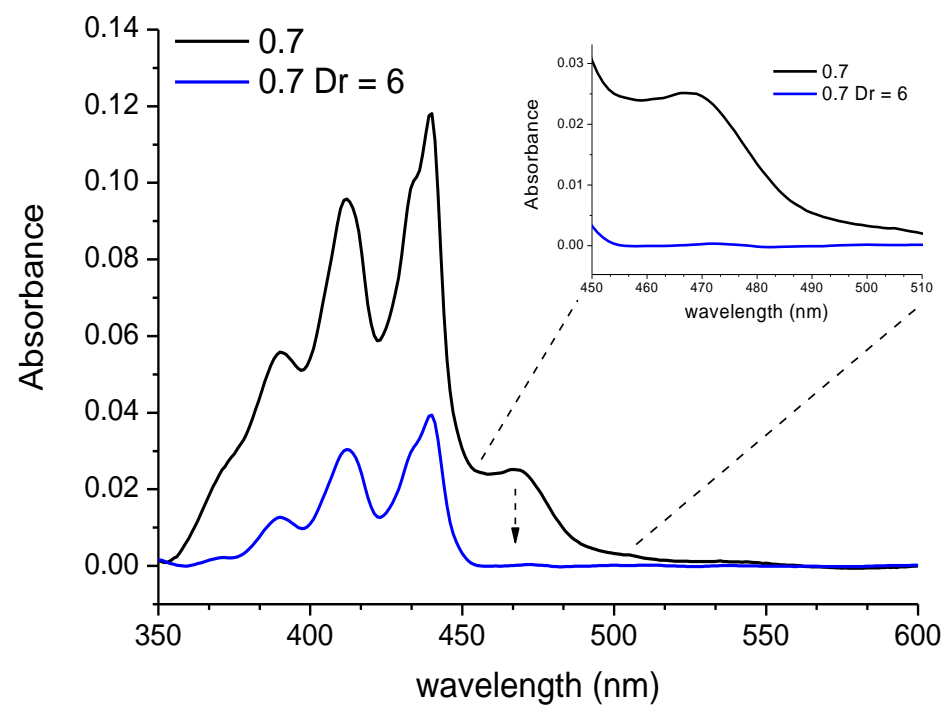

Fig. 5. UV-Vis absorption of a P-LLDPE- 0.7 film before and after stretching at $\mathrm{Dr}=6$ and enlargement of the region attributed to the absorption of $\mathrm{P}$ aggregates (inset). 
However, the strong decreasing of the absorption at $470 \mathrm{~nm}$ cannot be attributed to dilution phenomenon only. The uniaxial stretching were actually able to break-up $P$ aggregates leading to the collapse of the aggregation band, thus providing an absorption spectrum totally similar to that reported for P-LLDPE composites containing low dye concentration ( $\leq 0.1 \mathrm{wt}$. \%, Figure 2$)$.

The disruption of aggregates among perylene chromophores occurred after tensile drawing of P-LLDPE films was more evidently recorded in emission (Figure 6a): the band at 500-550 nm reduced its contribution whereas a significant increase of the luminescent intensity (at about $525 \mathrm{~nm}$ ) occurred at higher energy coming from isolated non-interacting dye molecules.
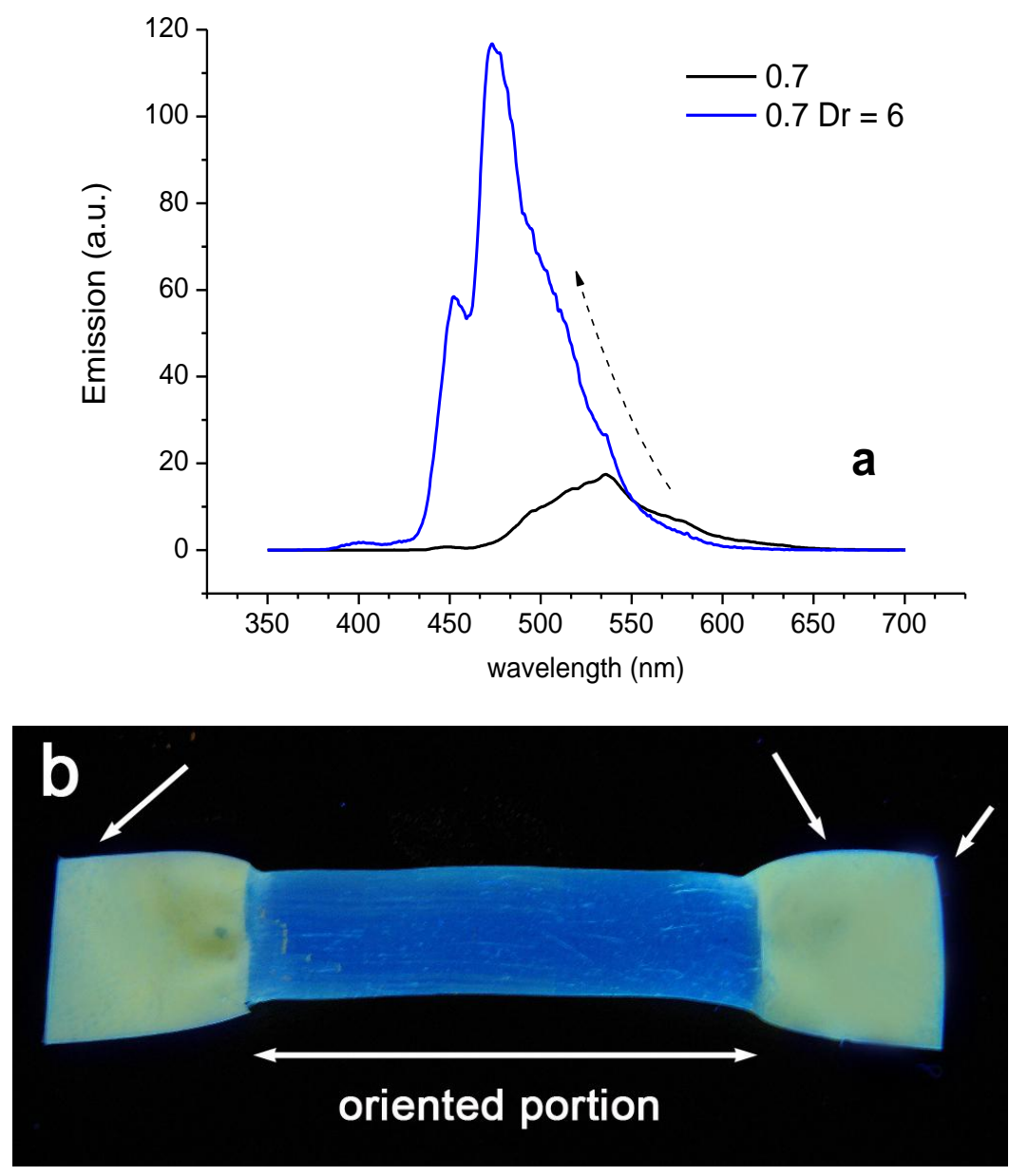

Fig. 6. (a) Emission of a P-LLDPE- 0.7 film before and after stretching at $\mathrm{Dr}=6$ and (b) digital image of the uniaxially oriented film under irradiation at $366 \mathrm{~nm}$ and indications of shearing stress caused during the preparation of the specimen.

The effect of polymer matrix deformation on the emission properties was also evaluated by exposing the oriented film to a long-range UV lamp at $366 \mathrm{~nm}$ (Figure $6 b)$. The disruption of the $P$ chromophoric aggregates clearly changed the luminescence of the film from pale yellow (unoriented portion) to bright blue (oriented portion) restoring the typical fluorescence of non-interacting perylene dyes.

By reducing $P$ concentration (i.e. on passing to P-LLDPE- 0.5 film) the variation of the optical properties with mechanical drawing became less evident due to a lower concentration of chromophoric aggregates within the undeformed LLDPE films. On 
the contrary, for the same reason, P-LLDPE-0.7 and P-LLDPE-1 composites, characterized by higher dye content and emission sensitivity to mechanical forces, show clearly portions of the film subjected to shearing stress.

At the same time, the dyes dispersed in the polymer as isolated molecules or aggregates, and exclusively located in the amorphous phase, undergo uniaxial alignment along the stretching direction. Dyes aggregates are generally destroyed during polymer deformation, which favours the uniaxial orientation of the single molecules. Once oriented, the composite films generally show a dichroic behaviour depending on dye dispersibility and chromophore structure complexity [28, 8, 29-32] In Figure 7, the UV-Vis absorption spectra of oriented P-LLDPE-0.01 ( $\mathrm{Dr}=6)$ were recorded in linearly polarized light by sending the polymeric tape a polarized radiation respectively parallel $\left(0^{\circ}\right)$ and perpendicular $\left(90^{\circ}\right)$ to the drawing direction.

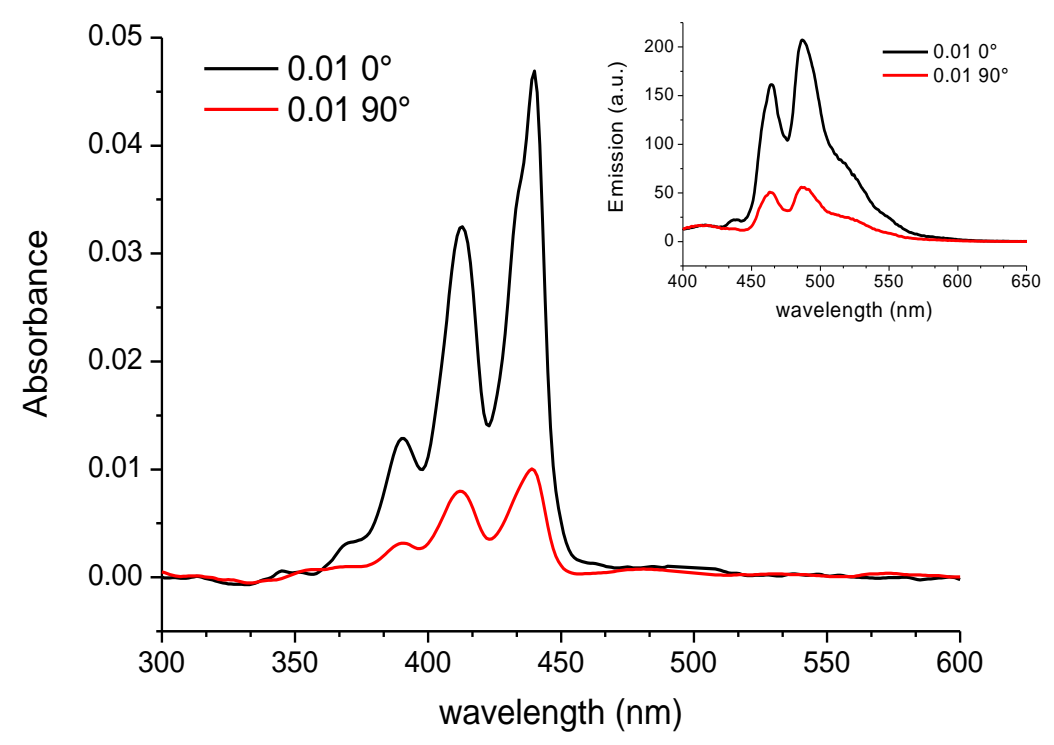

Fig. 7. UV-Vis absorption and emission (inset) spectra as a function of the polarization angle for P-LLBBS- 0.01 oriented film $(\mathrm{Dr}=6)$.

When the polarization of the incident light was parallel to the stretching direction, the film showed an absorption maximum pointed at about $440 \mathrm{~nm}$. On the contrary, in the perpendicular configuration the intensity of the resulted absorption band decreased, thus indicating an anisotropic (even if partial) behaviour of the perylene chromophores dispersed into the oriented polymer matrix. The anisotropic distribution of $\mathrm{P}$ molecules along the oriented polyethylene fibres was also investigated by fluorescence spectroscopy measurements in polarized light (Figure 7 inset). These have been performed by exciting the stretched tape with an unpolarized radiation and monitoring the dichroism of the emission through a linear polarizer. By rotating the direction of the polarizer from $0^{\circ}$ (parallel to the stretching direction of the film) to $90^{\circ}$ (perpendicular direction), the emission of the single perylene molecules reduces its intensity as reported for the absorption (Figure 7 ). In particular, on passing from 0.01 to $1 \mathrm{wt}$ - $\% \mathrm{P}$ concentration, the dichroic ratios calculated from the UV-Vis absorption spectra of the films dropped off, most likely due to the presence at 
high dye loading of considerable supramolecular aggregates that strongly limits the chromophore alignment (Figure 8).

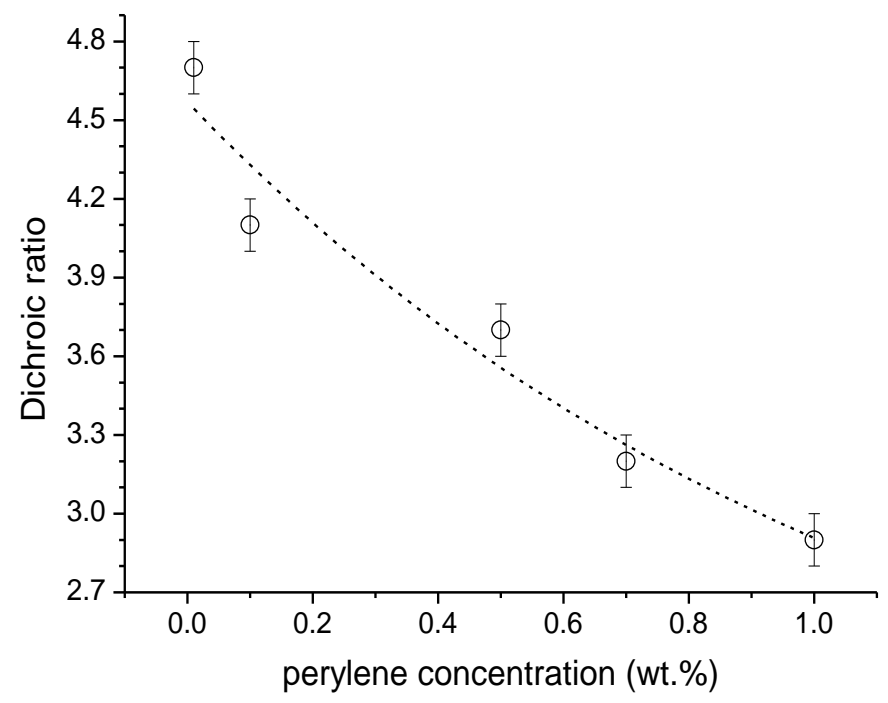

Fig. 8. Dichroic behaviour in absorption of P-LLDPE oriented films ( $\mathrm{Dr}=6$ ) as a function of perylene concentration.

The aggregation degree of $\mathrm{P}$ molecules played therefore an important role on the optical features of P-LLDPE composite films. At low $P$ concentration ( $\leq 0.1 \mathrm{wt} . \%) P$ dyes are almost molecularly dispersed as non-interacting and easily orientable molecules. By contrast, for $\mathrm{P}$ concentration higher than 0.1-0.5 wt.\%, the occurrence of molecular aggregates due to $\pi-\pi$ interactions between perylene chromophores not only influences the emission characteristics of the dispersed dyes but strongly limits their anisotropic distribution after uniaxial polymer drawing.

\section{Conclusions}

The incorporation of moderate amounts (from 0.01 to 1 wt.\%) of perylene $(\mathrm{P})$ into linear low density polyethylene (LLDPE) provided composite films with modulable optical properties both in absorption and in emission. In particular, perylene chromophores generate supramolecular aggregates promoted by $\pi$ - $\pi$ intermolecular interactions between the conjugated planar structure of the dyes when the concentration of $\mathrm{P}$ is increased over $0.1 \mathrm{wt} . \%$. The occurrence of this phenomenon effectively changed the emission of the dyes from a blue (non-interacting dyes) to pale yellow (interacting dyes) colour. The original blue colour of the film provided by the radiative transitions of the isolated $P$ molecules, was restored after polymer uniaxial stretching that promoted the breakup of the aggregates and the partial alignment of the single chromophore molecules along the drawing direction. The possibility of tuning the luminescence properties of LLDPE films simply by adjusting the supramolecular structure of perylene chromophores dispersed in the continuous matrix provided a very sensitive tool for determining the orientation in polymeric films and suggests various applications in the field of smart and intelligent films based on thermoplastic materials. 


\section{Experimental part}

\section{Materials}

Linear low density polyethylene (LLDPE, Dowlex SC 2107, Melt flow index, 190 ${ }^{\circ} \mathrm{C} / 2.16 \mathrm{~kg} 2.3 \mathrm{~g} / 10 \mathrm{~min}, \mathrm{~d}=0.917 \mathrm{~g} / \mathrm{cm}^{3}$, supplied by Dow Plastics, USA) was used as polymer host matrix.

Perylene $(P)$ was supplied by Aldrich and used without further purification.

Samples were named by listing guest molecule, polymer (abbreviated as LLDPE), concentration: e.g. P-LLDPE-0.02.

\section{Apparatus and Methods}

LLDPE mixtures were prepared by solution casting: about $300 \mathrm{mg}$ of LLDPE and the selected amount of $P$ were dissolved in $p$-xylene at $70{ }^{\circ} \mathrm{C}$. The solution was then casted into a Teflon ${ }^{\circledR}$ Petri dish and the film recovered after solvent evaporation. In order to obtain well-homogeneous polyethylene blends, the films were cut into pellets and compression-moulded in a Collin-mod.200M press at $180^{\circ} \mathrm{C}$ for $5 \mathrm{~min}$.

After removal from the press, the films were allowed to reach slowly room temperature $\left(\sim 5^{\circ} \mathrm{C} \mathrm{min}^{-1}\right)$. The films were generally analysed after 2-3 days. The thickness of the obtained films was in the range of $10-30 \mu \mathrm{m}$.

Optical absorption studies of dye solutions and polymer films were carried out at room temperature with the help of a Perkin-Elmer Lambda 650 equipped with motordriven Glan-Taylor linear polarizers.

Steady-state fluorescence spectra of solutions and polymer films were acquired under isotropic excitation with the help of a Perkin-Elmer Luminescence spectrometer LS55 controlled by FL Winlab software and equipped with the Front Surface Accessory: i.e., the position of the film sample was adjusted in the direction of the excitation beam in such a way that the optical axis of excitation and emission crossed in the film plane.

Solid-state drawings of the binary films were performed at room temperature or at $90{ }^{\circ} \mathrm{C}$ on a thermostatically controlled hot stage. The draw ratio $(\mathrm{Dr})$, defined as the ratio between the final and the initial length of the sample respectively, was determined by measuring the displacement of ink-marks printed onto the films before stretching. The absorption anisotropy were quantitatively evaluated by calculating the dichroic ratio $R$ (defined as $R=A_{/ /} / A_{\perp}$ ) of the absorption intensities $(A)$.

The film roughness was diminished, using ultra-pure silicon oil (Poly(methylphenylsiloxane), $710^{\circledR}$ fluid, Aldrich) to reduce surface scattering between the polymeric films and the Suprasil quartz slides, used to keep them planar. In the analysis of the absorption and emission data, the scattering contribution was corrected by the use of appropriate baselines. Origin 7.5, software by Microcal Origin ${ }^{\circledR}$, was used in the analysis of the absorption and emission data.

\section{Acknowledgements}

The authors wish to thank Dr. Alberto Schena for the help with blends preparation. Financial support by MIUR-FIRB 2003 D.D.2186 grant RBNE03R78E is kindly acknowledged. 


\section{References}

[1] Crenshaw, B. R.; Burnworth, M.; Khariwala, D.; Hiltner, A.; Mather, P. T.; Simha, R.; Weder, C. Macromolecules 2007, 40, 2400.

[2] Crenshaw, B. R.; Weder, C. Adv Mater (Weinheim, Ger) FIELD Full Journal Title:Advanced Materials (Weinheim, Germany) 2005, 17, 1471.

[3] Crenshaw, B.; Lowe, C.; Weder, C. Polymeric Materials Science and Engineering 2003, 88, 505.

[4] Pucci, A.; Ruggeri, G.; Bronco, S.; Bertoldo, M.; Cappelli, C.; Ciardelli, F. Progress in Organic Coatings 2007, 58, 105.

[5] Pucci, A.; Di Cuia, F.; Signori, F.; Ruggeri, G. Journal of Materials Chemistry 2007, 17, 783.

[6] Pucci, A.; Tirelli, N.; Ruggeri, G.; Ciardelli, F. Macromolecular Chemistry and Physics 2005, 206, 102.

[7] Mayer, J.; Szreder, T.; Szadkowska-Nicze, M.; Faucitano, A. J Polym Sci, Part A: Polym Chem FIELD Full Journal Title:Journal of Polymer Science, Part A: Polymer Chemistry 1998, 36, 1217.

[8] Luo, C.; Atvars, T. D. Z.; Meakin, P.; Hill, A. J.; Weiss, R. G. J Am Chem Soc FIELD Full Journal Title:Journal of the American Chemical Society 2003, 125, 11879.

[9] Vigil, M. R.; Bravo, J.; Atvars, T. D. Z.; Baselga, J. Macromolecules FIELD Full Journal Title:Macromolecules 1997, 30, 4871.

[10] Kunzelman, J.; Crenshaw, B. R.; Weder, C. Journal of Materials Chemistry 2007, $17,2989$.

[11] Crenshaw, B. R.; Kunzelman, J.C.; Sing, E.; Ander, C.; Weder, C. Macromol Chem Phys FIELD Full Journal Title:Macromolecular Chemistry and Physics 2007, $208,572$.

[12] Pucci, A.; Cappelli, C.; Bronco, S.; Ruggeri, G. Journal of Physical Chemistry B 2006, 110, 3127.

[13] Wuerthner, F. Chem Commun (Cambridge, $U$ K) FIELD Full Journal Title:Chemical Communications (Cambridge, United Kingdom) 2004, 1564.

[14] Wuerthner, F. Pure Appl Chem FIELD Full Journal Title:Pure and Applied Chemistry 2006, 78, 2341.

[15] Langhals, H. Heterocycles FIELD Full Journal Title:Heterocycles 1995, 40, 477.

[16] Birks, J. B.; Dyson, D. J.; Munro, I. H. Proc Roy Soc (London) 1963, 275, 575.

[17] Birks, J. B. Reports on Progress in Physics 1975, 38, 903.

[18] Jenekhe, S. A. Advanced Materials (Weinheim, Germany) 1995, 7, 309.

[19] Roberts, M. F.; Jenekhe, S. A.; Cameron, A.; McMillan, M.; Perlstein, J. Chemistry of Materials 1994, 6, 658.

[20] Kasha, M.; Rawls, H. R.; El-Bayoumi, M. A. Pure Appl Chem FIELD Full Journal Title:Pure and Applied Chemistry 1965, 11, 371.

[21] Philpott, M. R. Advan Chem Phys FIELD Full Journal Title:Advances in Chemical Physics 1973, 23, 227.

[22] Wurthner, F.; Thalacker, C.; Diele, S.; Tschierske, C. Chem--Eur J FIELD Full Journal Title:Chemistry--A European Journal 2001, 7, 2245.

[23] Donati, F.; Pucci, A.; Cappelli, C.; Mennucci, B.; Ruggeri, G. J Phys Chem B FIELD Full Journal Title:Journal of Physical Chemistry B 2008, 112, 3668.

[24] Loi, M. A.; Denk, P.; Hoppe, H.; Neugebauer, H.; Winder, C.; Meissner, D.; Brabec, C.; Sariciftci, N. S.; Gouloumis, A.; Vazquez, P.; Torres, T. Journal of Materials Chemistry 2003, 13, 700.

[25] Ward, I. M. Editor, "Structure and Properties of Oriented Polymers"; Applied Science Publishers Ltd.: London, 1975. 
[26] Eglin, A. M. M.; Palmans, A. R. A.; Tervoort, T.; Smith, P.; Weder, C. J Mater Chem 1999, 9, 2221.

[27] Eglin, M.; Montali, A.; Palmans, A. R. A.; Tervoort, T.; Smith, P.; Weder, C. Journal of Materials Chemistry 1999, 9, 2221.

[28] Tirelli, N.; Amabile, S.; Cellai, C.; Pucci, A.; Regoli, L.; Ruggeri, G.; Ciardelli, F. Macromolecules 2001, 34, 2129.

[29] Michl, J.; Thulstrup, E. W. Spectroscopy with Polarized Light: Solute Alignment by Photoselection, Liquid Crystals, Polymers, and Membranes"; VCH Publishers, Inc.: New York, 1995.

[30] Michl, J.; Phillips, P.J."Interaction of solutes with stretched polymers," Dep. Chem.,Univ. Utah,Salt Lake City,UT,USA., 1985.

[31] Phillips, P. J. Chemical Reviews (Washington, DC, United States) 1990, 90, 425. [32] Ward, I. M. "Structure and Properties of Oriented Polymers, 2nd Edition", 1997. 